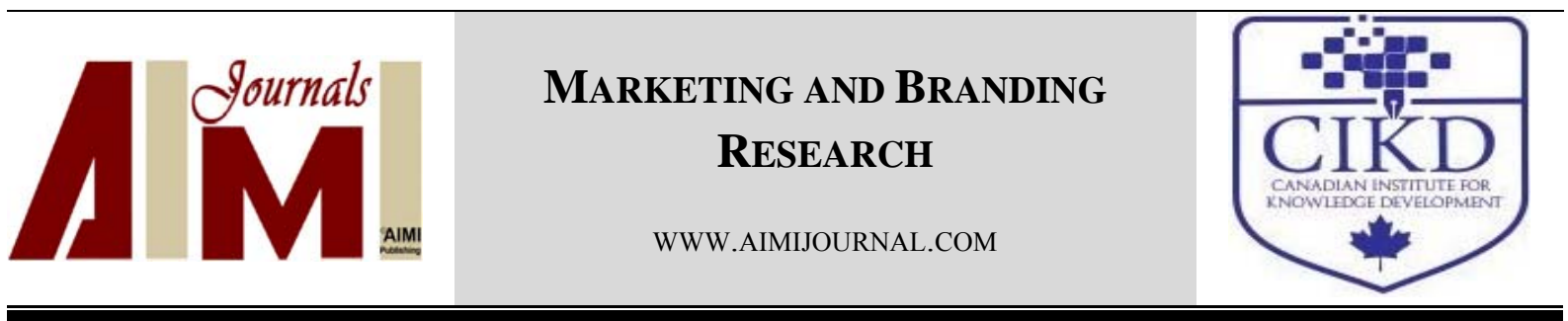

\title{
Economic Effects and Invasion of Low- Cost Carriers on the Bulgarian Air Market
}

\author{
E. Rancheva, T. Petkov, Stela Todorova* \\ Agricultural University - Plovdiv, Institute of Air Transportation, Agricultural University - Plovdiv
}

\begin{abstract}
Keywords:

Low-Cost Carriers, NonMarket Approaches, Airport Charges, Quality of Service

\begin{tabular}{l}
\hline Received \\
19 May 2018 \\
Received in revised form \\
28 June 2018 \\
Accepted \\
21 July 2018 \\
\hline
\end{tabular}

Correspondence: stelatodorova_au@hotmail.c om

Low cost aviation carriers already occupied a significant share of the Bulgarian aviation market for passenger transportation. The reality is that, thanks to the emergence of lowcost carriers, the number of passengers transported through airports is increasing. This, of course, is due to the low transportation prices offered by these carriers. The availability of such prices is related to the measures taken to reduce the operating costs and the successful tariff management policy achieved by the carriers. At the same time, some non-market methods are used to de facto subsidize the activity of carriers. Some intentions are declared or already established for setting up development funds for airports that redirect public funds to the carrier. The state approves airport charges that are lower than the actual costs of covering the fees in order to attract cheap operators. Tax relief is introduced for airlines that do not benefit from these concessions and take unfairly allocated airport charges for all carriers. The present report analyzes the policy related to the activities of low cost airlines on the Bulgarian market, including examples of dumping, inconvenience for passengers related to the step between the seats (quality of service that is due to low prices, something no organization or institution protects). Some suggestions and proposals are given in order to solve the raised problems.
\end{abstract}

CAIMI Journals

\section{Introduction}

The European airline industry has faced major threats such as cyclical slowdown, natural disasters, health pandemics, strikes, terrorism threats across the world and global economic recession (Tew, Zhen, Tolomiczenko, \& Gellatly, 2008; Wong \& Musa, 2011). In addition, 
the liberalisation of the European transport industry resulted in major changes for the European airline industry (Dobruszkes, 2009a; Doganis, 2006; Mak \& Go, 1995). One of the major outcomes of the liberalisation was the development of the European low-cost airlines (Collison \& Boberg, 1987; Graham, \& Shaw, 2008).

The first LCA in the worldwide airline industry was Southwest Airlines, launched in 1971. Southwest deviated from the airline industry's existing practice and business model (Porter, 1996). This innovative strategy has disrupted the existing airline marketplace (Bower \& Christensen, 1995; Markides, 2006). The definition of a LCA is ambiguous as there are numerous product differentiations within the low-cost sector. All the airlines share, however, a commitment to what Lawton (2003) terms the 'cult of cost reduction', a business model that offers low fares and strips out overall costs (Graham, B., Vowles T., 2006).

The airline industry has evolved through three "waves of dramatic change and restructuring that heavily affected consumers and their travel decision making" (Rubin \& Joy, 2005). "The first wave of change was brought about by the progressive economic deregulation of the global airline industry from the late 1970s through to $2000 \mathrm{~s}$ " (de Neufville, 2006). Deregulation prompted intense fare competition and, accompanied by industry expansion, it spurred airlines to seek improvements in efficiency through the development of the hub-and-spoke route to system and creating the notion of the "full service network carrier" (FSNC).

"In the latter half the 1980s, the heightened competitive conditions of a post-deregulation industry brought about the second wave of change; many airlines folded, consolidated, merged, or acquired through leveraged buyouts" (Rubin \& Joy, 2005). "Consumers are currently experiencing the third wave of change, which some believe to be the most transformative, as it involves changes to long-term aspects of the airline industry: competitive structure, ticket purchasing, route patterns and the emergence of low-cost airports" (de Neufville, 2008).

All LCA firms have prime core common characteristics such as efficiency, productivity, cost leadership leading to cheap fares (Lawton, 2003; O'Connell \& Williams, 2005, Ryan \& Birks, 2005; Wong \& Musa, 2011). Some authors also point to variations in the LCA sector (Ryan \& Birks, 2005). However, the key strategy of cost-cuttings leading to low fares creates a demand for LCA services (Barrett, 2004; Porter, 1996). Additionally, in economically difficult times, the demand for less expensive travel increases, which is to the LCA advantage (Bel, 2009; Mintel, 2007). Some of the above core business principles are not exclusive to the LCA sector, as they may also be characteristic of traditional airlines (Gil-Moltó \& Piga, 2008; O’Connell \& Williams, 2005).

After 1990, the main carriers were forced to change the nature of their activity in terms of costs and yields (average revenue generated by transported passengers or $\mathrm{km} / \mathrm{ton}$ ). As stated by Doganis (2001) "Cost reduction is no longer a short-term response to declining yields or falling load factors. It is a continued and permanent requirement if airlines are to be profitable" (pp. 222). They could react to low-cost competition by reducing their overhead costs (e. g. staff costs and use of Internet sales). In addition, new LCA companies can be set up on this massively low-priced market. This rivalry may undermine the market share of some LCA companies and intensify competitiveness (Doganis, 2006; Wong \& Musa, 2011). 
Low price tactics are necessary, but low price and cost reduction can be imitated by competitors in this industry (Lawton, 2003).

In order to respond to competition and maintain or increase their market share in an economic crisis, LCA firms need to rethink and change their business policy by building their competitive advantage beyond the low prices. Low prices, as an element of LCA's pricing strategy, may lead to an increase in short-term passenger numbers, but not a competitive advantage (Porter, 1985). Wong and Moussa (2011), on the other hand, argue that "The low tariff for low-cost airlines is the result of the operation's effectiveness rather than the lower standard of service." Dobrusky (2006) reports that "market is not yet healthy, and several airlines will probably disappear". "Applying a business model that is not adapted to the competitive market is the likely cause for some companies, such as Debonair, Sungold Airlines, Kiwi Airlines, to cease operations" (Porter, 1996). In response to the challenge of low-cost carriers, as of March 2005, airlines were reorganized by segmenting brands and creating "CWCs" with lower unit costs than those of parent carriers.

Graham and Vowles (2006) noted that legacy carriers have radically divergent responses and attitudes to the CWC strategy and that there is only very limited evidence that it constitutes an effective market response to low-cost competition. The first airline that successfully runs a mainline carrier and a separate, low fare airline-within-an-airline "should win the Nobel Prize in economics". (Rod Eddington, CEO British Airways, cited in Aviation Daily, 2004a, FENIX FUND - Bulgaria. Development Fund for South-Central Region/http://www.phoenixfund-bg.com/bg/2015-01-19-18-57-01/membership-bg). This strategy is of increasing importance, because LCAs redefine the parameters of air transport demand in North America, Europe and, now, Asia-Pacific (including both Asia and Australasia).

Of concern here is the segmentation of brands and markets as mainline carriers reposition themselves to meet the challenge of LCCs, most particularly acute on shorter-haul operations, through the creation of subsidiary CWCs with lower unit costs than the parent airline. In many countries, great attention is devoted to the development of regional airports to help the economic development of some decentralized areas. "Development of Regional Airports comes as an appropriate and timely reminder that regional airport development is based on economics and practical planning. It is well recommended" (The Aerospace Professional, December, 2011).

The continuous development of low-cost air carriers has given a further impulse to the revaluation of regional airports. In fact, low-cost air carriers prefer to use regional airports for many reasons as follows: reduced aviation costs at the airport, competitive taxi and turnaround times, availability of airport capacity due to low traffic congestion and so on. In addition, they can also benefit from start-up, within the rules of compatibility established by the Articles 87-89 of the EC Treaties and the Community guidelines on financing of airports and start-up aid to airlines departing from regional airports. Particularly, Article 87(3)(a) and (c) applied in 2006 in relation to aid for undertakings financing the building of a hangar in such regions (Postorino, 2010). Other important issues related to the expansion of larger airports are difficulties and delays at airports, as well as environmental considerations. In fact, most important airports are quite near to cities and produce important negative effects 
due to both air services (as noise and pollution) and airport land accessibility (as road congestion). This is also the case for EU policies aimed at promoting the re-evaluation of regional airports in several EU countries.

As stated by the European Commission (EC), 'Regional airports are important to the development of an integrated European air transport network. In this respect, it would be desirable to unlock existing latent capacity at regional airports provided that Member States respect Community legal instruments relating to state aids. Global Navigation Satellite Systems could play a significant role for increasing capacity and flexibility of operations at those airports without increasing the cost of local infrastructure. Member States should endeavour to improve the accessibility of such airports by rail and road to allow them to act as reliever airports.' ('An action plan for airport capacity, efficiency and safety in Europe', Brussels,Jan2007, Retrieved from

/www.eurocontrol.int/sites/default/files/news/content/documents/nm/safety/agc-action plan.pdf).

\section{Method}

The Bulgarian aviation industry encompasses: community air carriers; Operators carrying out plant protection flights with valid AOCs for specialized aviation operations (AOC - SAR); Aviation Infrastructure Enterprises (International Airports and Air Navigation Services Provider, Base Service and Repair Maintenance and Approved Organizations under Regulation (EU) No 2042/2003 (Part M, Part 145, Part 147), Ground Operators in airports, training centers (under Regulation (EU) No 1178/2011 and Ordinance 27, Ordinance on the Fees for the Use of Airports for Public Use and for Air Navigation Services in the Republic of Bulgaria, St. Newspaper 21/ 2017), airfield operators, ticket sales staff (cannot be covered).

The main priorities of Bulgaria's transport policy in the transport sector are: liberalization of the transport market, creation of favorable conditions for the development of private, competitive transport companies in all sectors of transport. This is related to the transformation of the country's transport network into a competitive, efficient transport bridge between Western and Central Europe. The foundations of the new Bulgarian economy are in the services sector, mostly in tourism and the real estate market, according to the authoritative British Business Website/www.buisnessonline.com/. Among the negative sides of the country is the lack of low fare aircraft carrier companies, which would contribute to the transformation of the tourism industry and the real estate market in Bulgaria.

The accession of Bulgaria to the European Community and the development of the tourism sector and the real estate market implies for an increase in passenger traffic to and from Bulgaria, as well as the emergence of low-cost company/interest. Since September 2005, its first official low-cost airline - Wizz Air - has begun its operations. The company flies in the Sofia - Budapest destination with a regular flight, four times a week.

On September 18, 2005, the first licensed regular low-cost passenger airline took place on the Sofia-Budapest destination serviced by the Hungarian airline Wizz Air. Since autumn 2006n competition between airlines has been steadily rising. No matter how frightening it is for airline companies to fight for the sky, consumers benefit from it, provided they have enough culture to check their carrier carefully. Apart from the prices, they can also choose 
from the quality of services. In 2007, Bulgaria initiated the Europe-wide airspace agreement along with 38 countries. With this, the bilateral agreements according to which only air carriers selected by the two countries to fly to and from Bulgaria, automatically lapsed. With the signing of the document in Bulgaria, every airline that meets EU safety requirements is landing and taking off. Thus, the competition between air carriers for the sky has exacerbated even more.

The membership of the Republic of Bulgaria in the European Union obliges us to apply the Union law. In the field of aviation this means, first of all, the liberalization of access to the air transport market. One of the results is the penetration of low-cost airlines (LCA) on the market and a gradual increase in their share of passenger transportation for regular international airlines (RIA).

\section{Results and Discussion}

Table 1 and Figure 1 shows the data of the dynamics (by years) of the passengers carried and the number of RIA take-offs and landings of LCA airlines. The respective shares of LCA from the total passenger flow and the total number of routes (take-offs/landings) of LCA at Sofia airport are also indicated.

Table 1

Data on the Activity of Low-cost Airlines (LCA) at Sofia Airport

\begin{tabular}{lccccc}
\hline Indicators & 2007 & 2008 & 2009 & 2010 & 2011 \\
\hline Total International Schedule (PAX), thousands & 2482.2 & 2880.2 & 2782.6 & 2959.8 & 3141.3 \\
i. e. low-cost PAX, thousands & 106.8 & n.a. & 695 & 651.2 & 942.4 \\
Share of low-cost PAX, \% & 4.3 & n.a. & 25 & 22 & 30 \\
Total movements, number & 30796 & 34870 & 33353 & 34321 & 34826 \\
Movements of LCAs, number & 2905 & n.a. & 4670 & 5491 & 7662 \\
Share of movements, $\%$ & 9.4 & n.a. & 14 & 16 & 22 \\
\hline
\end{tabular}

Table 1

(continue)

\begin{tabular}{lccccc}
\hline Indicators & 2012 & 2013 & 2014 & 2015 & 2016 \\
\hline Total International Schedule (PAX), thousands & 3139.5 & 3198.6 & 3526.7 & 3797.8 & 4720.4 \\
i. e. low cost PAX, thousands & 784.9 & 863.6 & 1128.5 & 1291.2 & 2105 \\
Share of low-cost PAX, \% & 25 & 27 & 32 & 34 & 44.6 \\
Total movements, number & 31289 & 29493 & 32015 & 33994 & 41046 \\
Movements of LCAs, number & 5006 & 7963 & 7363 & 7818 & 13572 \\
Share of movements, \% & 16 & 15 & 23 & 23 & 33 \\
\hline
\end{tabular}

For the ten-year period 2007-2016, the total number of RIA passengers increased from 2482.2 thousand to 4720.4 thousand or rose by 1.9 times. For the same period, the number of passengers traveled by LCA through RIA increased from 106.8 thousand to 2105 thousand or increased by 19.7 times. At the same time, the share of RIA passengers transported by LCA increased from $4.3 \%$ to $44.6 \%$, i.e. more than 10 times. 


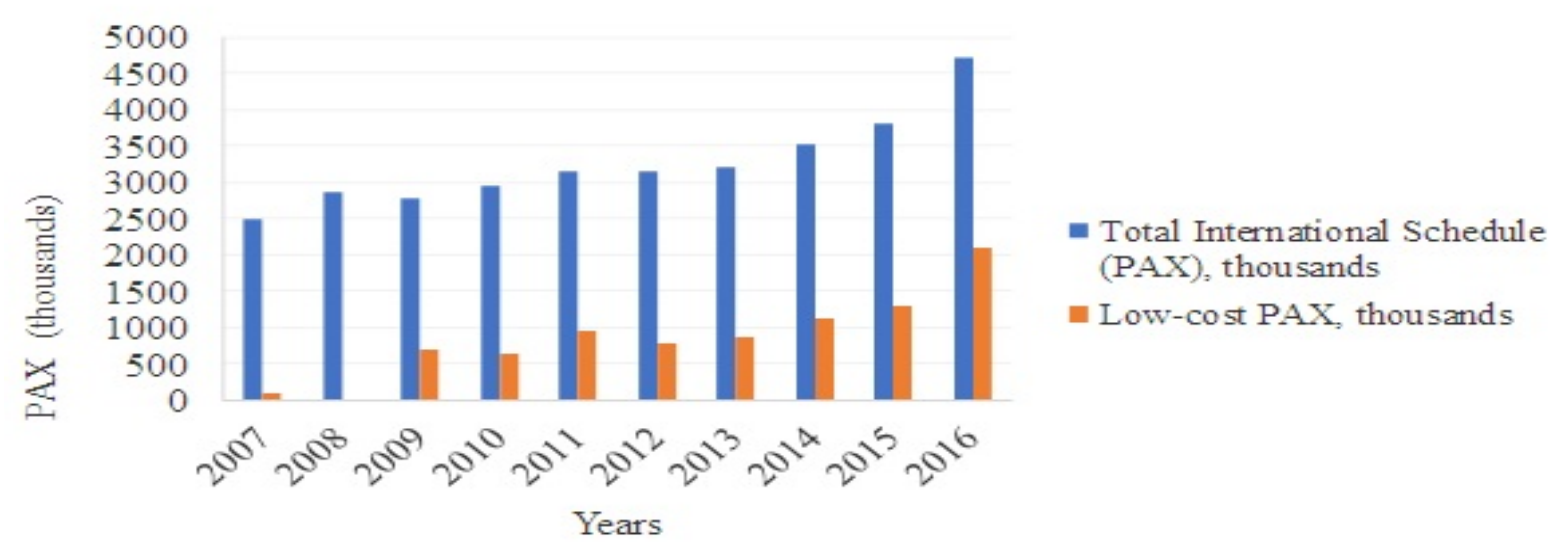

Figure 1. Total international schedule (PAX) and low-cost PAX for the period 2007-2016 (thousands)

Undoubtedly, the share of LCA passengers transported through RIA and its increase is mainly due to the low tariffs offered, the development of the network of routes offered by LCA, the attraction of passengers who have not yet been using air transport, and inadequate response from traditional carriers. Due to this increase in passenger transportation and the increase in the positive indicators for tourism, we are witnessing some problems that are occurring to the LCA invasion on the Bulgarian market. Consideration is given to actions that call into question the correct application of the ICAO rules and standards related to the estimation of the amount of airport charges. As a rule, ICAO standards in this area have been reaffirmed by EU legislation.

\section{Advertised Minimum Prices of Air Carriers}

In mass media, including the LCA and airport websites, flights are periodically announced from Sofia by low-budget aviation carriers with a ticket price of $9 €$ or even lower. We have to bear in mind that the amount of airport charges for departing passengers and the security fee is $11 €$. Even if we fall into the hypothesis of airport tax concessions, there will still be some suspicion of dumping, especially since the carrier has to pay a landing charge as well as air navigation charges. Separately, the carrier also has inherent costs for staff, fuel, aircraft maintenance, ground handling. Even if a policy of dumping is not formally enforced, somebody has to cover the mentioned costs and that is likely to be the rest of the passengers.

\section{Airport Charge Base Airport Landing Fee}

In order to attract carriers, with the expectation of an increase in the number of movements, consequently the increase of the landing fee revenues as a result of a higher number of landings in 2010, and landing fee in Bulgaria was reduced by half and by 2014 and a new tariff structure was introduced. The landing fee at Plovdiv Airport (excluding discounts / reductions) is lower than the amount of the airline charge applicable to other international airports. For example, for an airplane with a maximum take-off mass of $78 \mathrm{t}$ (A320), the landing charge at Plovdiv Airport is $390 €$. At the same time for Sofia Airport, the fee is $842.4 €$, and for Burgas and Varna airports $-630 €$. The fact is that the number of landings of commercial airplanes at Plovdiv airport is $2-3 \%$ of that at Sofia airport (6-7\% of all landings 
at Burgas airport and $8-10 \%$ from Varna airport respectively). It is clear that the amount of the fee is not cost-oriented and, specifically for Plovdiv Airport, it is normal to expect a shortage of funds to cover the costs related to this fee. The non-compliance of the landing charge with the cost-orientation criterion is a significant violation of the ICAO regulatory framework and recommended international standards and guidelines.

\section{Introducing Discounts for “Traffic Transportation Development"}

To encourage the development of traffic at Sofia Airport and Plovdiv Airport, several types of discounts are provided for the landing charge payable by the airline carrier at Sofia Airport. Upon the introduction of a new regular full-year route within Europe, the respective carrier pays a reduced landing fee, with the reductions being $80 \%, 50 \%, 30 \%$, and $20 \%$ respectively for the first, second, third and fourth years of the route. For a new seasonal international passenger route for the first flight season, a $40 \%$ reduction is foreseen. A yearon-year increase in the capacity of an existing passenger route when changing the type of aircraft with such aircraft with a higher take-off mass and more passenger seating than onroute is subject to a one-year reduction of the first flight on the route by $50 \%$ for the MTOW. A discount on the landing fee is also introduced depending on the number of movements performed on international routes made by the same carrier: if more than 3,000 movements were realized, the decrease is $3 \%$, with 5,000 movements the decrease is $5 \%$ from 6.5 thousand movements the decrease is $10 \%$, etc. One-time incentive discounts (first flight on a new passenger route $-99 \%$, first flight of a new carrier - $99 \%$ and "flight related to an air transport in positive light" - 50\%) were also introduced.

The implementation of this policy, including cumulative and enforcement, results in a significant reduction in the landing charge payable by the relevant LCA. It is considered as a fact that traditional carriers do not actually have the financial capability to put more aircraft into operation. Typical for LCA is the ability to deploy resources to put into operation a larger amount of aircrafts. Thus, LCA can offer lower transportation rates. At the same time, the significant reduction of the landing charge, practically relevant only to LCA, cannot prove the income statements to cover the costs associated with that fee, thus the rest - the traditional carriers - by paying the basic amount of the fee, cover the shortage. For Plovdiv airport, in order to boost the volume of traffic, discounts are also applied depending on the monthly number of landings of an operator with aircrafts that have maximum take-off mass exceeding 5,7 tones. With a landing number of 4 to 15 per month landing charges for the same aircraft will already be $351 €$. From 16 to 22 landings per month the amount of the fee will be $312 €$, and for a monthly number of landings from 23 to 26 the amount of the fee will be $273 €$. If there are daily landings (i.e., for a monthly landing number of 27 to 31 ), the fee is $€ 235$.

\section{Passenger FEE/TAX}

For Plovdiv airport, each departing passenger (over 2 years old) is due a base fee is $6 €$. Incentives are provided, i.e. discounts. Thus, for a monthly number of passengers departing from 600 to 2500 , the fee is reduced to $4.50 €$. This is equivalent to five flights a month, with 
120 passengers aboard, i.e. about one flight a week. Therefore, a guaranteed payment of the lower amount of the passenger tax is achieved or $25 \%$ lower than the nominal fee.

For Sofia airport and base amount of departure ticket of $5.50 €$, discounts are introduced in relation to the number of passengers transported by the same carrier for 12 consecutive months. Thus, in the case of transportation of 100,000 to 200,000 passengers, the reduction is $0,5 €$ per passenger and in the case of 200,000 to 300,000 passengers, the reduction is $0,75 €$, with the transport of 300,000 to 400,000 passengers reduced is $1 €$ and so on.

We try to model the implementation of the incentive policy related to the number of passengers transported to Sofia airport. The data for 2016 testify that LCA " $X$ " had transported 1471.9 thousand passengers on regular international routes. Another LCA "Y" carried 491.2 thousand passengers respectively. Entering the incentive scheme envisaged for 2017, we conclude that LCA " $X$ " qualifies for a carrier with a number of passengers within 12 months of more than 500 thousand. For LCA " $X$ " a reduction of $1.35 €$ is foreseen for the departing passenger, in other words it will be $4.15 €$ per passenger, older than 2 years. Accordingly, for the LCA "Y", there are more than 200,000 departing passengers, thus the reduction of the fee is $0.75 €$ and the applicable fee will be $4.75 €$. Conversely, for the departing passengers LCA " $\mathrm{X}$ " will pay a total of 3054.4 thousand $€$, and LCA " $Y$ " will pay respectively 1166.6 thousand $€$. The amount for the enterprise will be $€ 4221$ thousand. If the carriers paid the standard fee without a reduction $(5.5 €)$, the total sum collected would be 5398.5 thousand $€$, i.e. the amount actually collected is by 1177.5 thousand $€$ less. As long as the amount of airport charges has to be cost-oriented, it can be argued at first that the shortage of these 1177.5 thousand $€$ will have to be covered by other airlines that do not benefit from a discount to stimulate the development of air traffic.

\section{Non Market Forms of Aid with the Help of Public Funds}

The low-cost airline receives locally subsidized compensation for cheap flights. They call this "marketing support". It is provided to a subsidiary of LCA, which in return advertises the region to potential passengers. In 2010, the municipalities of the Plovdiv region established requirements as a condition of the LCA Fund for Advertising of Plovdiv, of the region and of Bulgaria - "Plovdiv Airport Development Fund - The South Gate of Bulgaria". (From their budgets, upwards by 0.5 leva per capita is set aside, and by 2015 the contribution to the airport fund is already 1 lev per capita). In 2015, a second fund built - the non-profit association "Development Fund for the South Central Region - III-4 Phoenix Fund"(registered by Decision 22 of January 22, 2015 on company file 162/2014 of the Plovdiv District Court). The funds are raised and collected from membership fees and donations through companies and individuals. The aim was to raise 50000 leva per year from the members of the fund.

There is no evidence that the provided co-financing of LCA activities will lead to an increase in the incomes of the foreign tourists being transported. On the other hand, the funds collected are certainly not used for the purpose of the residents of the municipalities participating in the fund. Ultimately, the benefits of giving the carrier additional funds are potentially utilized by lower-priced flights that the passengers use.

Another form of assistance with public funds is offered by Fraport Twin Star Airport Management AD, the concessionaire of the airports in Bourgas and Varna. The company has 
proposed the establishment of a regional fund for the development of air links to and from Varna airport. Funding is achieved probably at the expense of part of the tourist tax. The accounts are that a new year-roundtrip airline to Varna will bring about 60 thousand passengers a year. The financial support required for 4 flights a week for one year will be in the range of 150-200 thousand euros. If the three maritime municipalities - Varna, Balchik and Kavarna allocate $20 \%$ of the revenues from the tourist tax, the accumulated funds for one year will be about 500 thousand euro, sufficient for the commencing of 3-4 new air lines. Similar intentions are expressed in relation to Bourgas Airport.

The above motivation testifies that on the basis of Art. 61p. of the Local Taxes and Fees Act (Law on Local Taxes and Fees in Bulgaria St. Newspaper 97 /2016). A form of circumvention of is offered or non-application of Art. 11, item 2 of the Law on Tourism.

\section{Customer Service}

Low prices offered by cheaper oriented airlines, the so-called low cost carrier, are a twoedged sword for their service users. They need to read in advance and very carefully the general conditions offered by low-cost carriers. The main disadvantages are: BG-3.6 3/4 often land at distant airports in early morning or late evening hours, resulting in additional transport costs for travel. $3 / 4$ in the price of the plane ticket does not include airport charges, which are about 20-30 euros and are paid twice - on departure and on arrival. 3/4 Food and beverages on board are for a fee. (Even though some traditional airlines, such as Austrian Airlines, are also paid for on board.) $3 / 4$ These airlines are in most cases not responsible for dropping transfers between their flights. $3 / 4$ usually there are no reserved seats on the plane. Low price hit is a matter of lottery because the lowest rates are available for only a dozen places, after that prices are rising. Frequent cheap airlines are often appearing to attract passengers with low bids but then unable to fly because of a lack of permission from aviation authorities. After the number of unpleasant cases of unplanned air transport passengers in Bulgaria from Beck Air and Easy Fly, it is the recommendation of the air specialists to check if this airline is registered and whether it has a license to undertake flights to and from Bulgaria. This is easily done and checked through the website of the Civil Aviation Administration (CAA) at the Ministry of Transportation http://www.caa.bg/page_caa_bg_airopers.htm.

With accepting the low transportation rates offered by LCA, the passenger is in fact not given the opportunity to object to the non-insurance of the carrier to certain accommodations, such as an ergonomic step between the seats. The more comfortable seat spacing requires additional payment. The passenger has no independent protection to provide a scientifically grounded level of comfort when traveling by air, against systematically imposed by carriers additional conditions and restrictions justified by the low cost of transportation.

\section{Conclusion}

The "Methodology for determining airport charges to be collected by an airport operator at an airport with an annual traffic of more than 5 million passengers or by the airport operator with the largest number of passenger services on the territory of the Republic of Bulgaria (Sofia airport, "EAD, Annual Financial Report 2015/2014/2013/2012, Commercial Register, https://public.brra.bg) - should be updated (ICAO Policies in Relational Aviation 
Components and Services for Aeronautical Service, ICAO Doc 9082, ed. 8, Annex 1 to Article 1, pp. 31, paragraph 3) to justify the achievement of cost-orientation of airport charges when applying discounts and reductions. A methodology for determining the amount of airport charges for other airports outside Sofia airport, taking into account the costorientation of airport charges when applying discounts and reductions, should be developed and published. The possibility of applying non-market-based approaches in relocating public funds for actual airline borrowing should be limited. It is necessary to adopt standards (unbundled with manufacturers 'and carriers' lobbies) to provide, without additional payment, a mandatory complex of amenities and services to be achieved by all carriers, regardless of traditional or low-cost.

\section{References}

Bel, G. (2009). How to compete for a place in the world with a hand tied behind your back: The case of air transport services in Girona. Tourism Management, 30(4), 522-529.

Barrett, S. D. (2004) How do the demands for airport services differ between full-service carriers and low-cost carriers? Journal of Air Transport Management, 10, 33-39.

Bower, J. L., \& Christensen, C. M. (1995). Disruptive technologies: Catching the wave. Harvard Business Review, 73(1), $43-53$.

Collison, F. M., \& Boberg, B. K. (1987). Marketing of airline services in a deregulated environment. Tourism Management, 8(3), 195-204.

Directive 2009/12 / EC of the European Parliament and of the Council of 11 March 2009 on airport charges / Official Journal of the European Union, L 70/14.03.2009, pp.11-16.

Decision to determine the amount of airport charges at Sofia airport № 553/28.10.16, https://www.sofia-airport

De Neufville, R. (2006). Accommodating low-cost airlines at main airports. International Airport Review, 1, $62-65$.

De Neufville, R. (2008). Low-cost airports for low-cost airlines: Flexible design to manage the risks. Transportation Planning and Technology, 31(1), 35-68.

Dobruszkes, F. (2009a). Does liberalisation of air transport imply competition? Lessons from the European case. Transport Policy, 16, 29-39.

Dobruszkes, F. (2009b). New Europe, new low-cost air services. Journal of Transport Geography, 17, 423-432.

Doganis, R. (2006). The airline business in the 21st century (2nd ed). London: Routledge.

Gil-Moltó, M., \& Piga, C. A. (2008). Entry and exit by European low cost and traditional carriers. Tourism Economics, 14 (3), 577-598.

Graham, B., \& Shaw, J. (2008). Low-cost airlines in Europe: Reconciling liberalization and sustainability. Geoforum, 39(3),1439-1451.

Graham, B., \& Vowles, T. M. (2006). Carriers within carriers: A strategic response to low-cost airline competition. Transport Reviews, 26(1), 105-126.

Gil-Moltó, M., \& Piga, C. A. (2008). Entry and exit by European low cost and traditional carriers. Tourism Economics, 14(3), 577-598.

Lawton, T. C. (2003). Managing proactively in turbulent times: Insights from the low-fare airline business. Irish Journal of Management, 24(1), 173.

Mak, B., \& Go, F. (1995) Matching global competition: Cooperation among Asian airlines. Tourism Management, 16(1), 6165 .

Markides, C. (2006). Disruptive innovation: in need of better theory. Journal of Product Innovation Management, 23, $19-25$.

Mintel. (2007). No-frills/Low-costs Airlines - UK - July 2007, [online], Retrieved from http://academic.mintel.com/sinatra/oxygen_academic/search_results/showand/display/id=21 9233/display $/ \mathrm{id}=219233 /$ display $/ \mathrm{id}=288883$ ? select section $=\overline{2} 19233$.

O’Connell, J. F., \& Williams, G. (2005). Passengers' perceptions of low cost airlines and full service carriers: A case study involving Ryanair, Aer Lingus, Air Asia and Malaysia Airlines, Journal of Air Transport Management, 11, $259-272$. 
Postorino, M. N. (2010). Development of regional airports in eu theoretical analyses and case studies. Unites states: WIT Press.

Porter, M. E. (1985). Competitive advantage: Creating and sustaining superior performance. London: Free Press.

Porter, M. E. (1996). What Is Strategy? Harvard Business Review, 74(6), 61-78.

Rubin, R. M., Joy, J. N. (2005). Where are the airlines headed? Implications of airline industry structure and change for consumers. The Journal of Consumer Affairs, 39(1), 215-228.

Ryan, C., \& Birks, S. (2005). Passengers and low cost flights: Evidence from the trans-tasman routes. Journal of Travel \& Tourism Marketing, 19(1), 15-27.

Tew, J. P., Zhen L., Tolomiczenko, G., \& Gellatly, J. (2008). SARS: Lessons in strategic planning for hoteliers and destination marketers. International Journal of Contemporary Hospitality Management, 20(3), 332-346.

Wong, K. M., \& Musa, G. (2011). Branding satisfaction in the airline industry: A comparative study of Malaysia Airlines and Air Asia. African Journal of Business Management, 5(8), 3410-3423. 